Article

\title{
Chemical Regeneration of Thermally Conditioned Basalt Fibres
}

\author{
Matteo Lilli ${ }^{1, *(\mathbb{D})}$, Fabrizio Sarasini ${ }^{1}\left(\mathbb{D}\right.$, Lorenzo Di Fausto ${ }^{1}$, Carlos González ${ }^{2}(\mathbb{D}$, \\ Andrea Fernández ${ }^{2,3}$, Cláudio Saúl Lopes ${ }^{2,4}$ and Jacopo Tirillò ${ }^{1, *}$ \\ 1 Department of Chemical Engineering Materials Environment \& UdR INSTM, Sapienza-Università di Roma, \\ 00184 Roma, Italy; fabrizio.sarasini@uniroma1.it (F.S.); difaustolorenzo@gmail.com (L.D.F.) \\ 2 IMDEA Materials, C/Eric Kandel 2, 28906 Getafe, Spain; carlosdaniel.gonzalez@imdea.org (C.G.); \\ andrea.fernandez@imdea.org (A.F.); claudio.lopes@list.lu (C.S.L.) \\ 3 Materials Science and Engineering Department, University Carlos III of Madrid, 28911 Leganés, Spain \\ 4 Luxembourg Institute of Science and Technology, L-4362 Esch-sur-Alzette, Luxembourg \\ * Correspondence: matteo.lilli@uniroma1.it (M.L.); jacopo.tirillo@uniroma1.it (J.T.); \\ Tel.: +39-06-4468-5314 (M.L.); +39-06-4458-5908 (J.T.)
}

Received: 7 September 2020; Accepted: 22 September 2020; Published: 24 September 2020

check for updates

\begin{abstract}
The disposal of fibre reinforced composite materials is a problem widely debated in the literature. This work explores the ability to restore the mechanical properties of thermally conditioned basalt fibres through chemical treatments. Inorganic acid (HF) and alkaline $(\mathrm{NaOH})$ treatments proved to be effective in regenerating the mechanical strength of recycled basalt fibres, with up to $94 \%$ recovery of the strength on treatment with $\mathrm{NaOH}$. In particular, $\mathrm{HF}$ treatment proved to be less effective compared to $\mathrm{NaOH}$, therefore pointing towards a more environmentally sustainable approach considering the disposal issues linked to the use of HF. Moreover, the strength regeneration was found to be dependent on the level of temperature experienced during the thermal treatment process, with decreasing effectiveness as a function of increasing temperature. SEM analysis of the fibres' lateral surfaces suggests that surface defects removal induced by the etching reaction is the mechanism controlling recovery of fibre mechanical properties. In addition, studies on the fracture toughness of the regenerated single fibres were carried out, using focussed ion beam (FIB) milling technique, to investigate whether any structural change in the bulk fibre occurred after thermal exposure and chemical regeneration. A significant increase in the fracture toughness for the regenerated fibres, in comparison with the as-received and heat-treated basalt ones, was measured.
\end{abstract}

Keywords: basalt fibres; recycling; mechanical properties; heat treatment; fracture mechanics; fracture behaviour

\section{Introduction}

The growing use of composite materials in many applications has led the industrial and academic composites community finding environmentally friendly solutions for the management and disposal of composite waste. In the last decade, because of the EU Waste Directive, the use of the landfill waste disposal system is decreased, although it apparently remains the cheapest approach.

The lack of cost-effective recycling methods for composite materials is one of the biggest challenges facing the composite materials industry. Nowadays, thermal recycling processes such as pyrolysis or chemical recycling processes such as solvolysis have been developed on an industrial scale to achieve partial recovery of glass fibres [1]. However, after the thermal treatment process, the tensile strength of the single glass fibres strongly decreases [2] and, because of this, it is no longer possible to use these fibres for a new semi-structural composite. For these reasons, the scientific community has recently 
been focusing on alternatives to the most common synthetic fibres. In this perspective, the use of fibres of mineral origin, such as basalt, is a plausible solution for the reduction of the environmental impact of composite materials [3,4]. Due to its lower environmental impact, its higher chemical stability and similar mechanical properties, basalt fibre has proven to be a viable alternative to glass fibres as a reinforcement in composite materials [5].

Unfortunately, similar to the case of composite materials reinforced with glass fibres, composite materials with basalt fibres show a drastic decrease in mechanical properties after the typical thermal recycling process [6-9]. In a previous work, basalt fibres heat treated at $600{ }^{\circ} \mathrm{C}$ for $1 \mathrm{~h}$ in air showed a decrease of $\sim 75 \%$ of the original tensile strength [10]. Several mechanisms, classified as superficial and structural phenomena, have been proposed as responsible for the loss of fibre strength [11-13], even though this is still an open issue in the literature. Lilli et al. [14] have recently shown by single edge notch tension and nanoindentation micro-pillar splitting methods that microstructural changes occur in the fibres after thermal exposure.

Thomason and co-workers $[15,16]$ demonstrated that the tensile strength of heat-treated glass fibres can be significantly recovered by a post treatment in an acid or an alkaline solution. Yang et al. [15], in a pioneering work on strength regeneration of glass fibres, investigated a treatment based on $1 \mathrm{v} \%$ HF aqueous solution and reported almost a triple increase in the strength of degraded fibres after a $3 \mathrm{~min}$ treatment. This approach was also effective at the composite scale, for a chopped strand mat in an epoxy matrix. Later, Thomason et al. [16] proposed a more environmentally friendly chemical treatment based on a $3 \mathrm{M} \mathrm{NaOH}$ solution for $10 \mathrm{~min}$ at $90^{\circ} \mathrm{C}$ compared to hydrofluoric acid. The results of single fibre tensile testing displayed a maximum recovery of $75 \%$. Bashir et al. [17] carried out a detailed study in order to assess the effectiveness of other alkaline treatments $(\mathrm{KOH}$ and $\mathrm{LiOH})$ in restoring the tensile strength of thermally degraded glass fibres. Results suggested that $\mathrm{LiOH}$ was unable to regenerate the strength while $\mathrm{KOH}$ proved to be a milder glass fibre etchant compared to $\mathrm{NaOH}$, producing improvements in fibre strength only at higher molarity and longer treatment times. These treatments allow to obtain a closed-loop recycling process [15], resulting in a considerable reduction of the $\mathrm{CO}_{2}$ produced [18]. These studies on chemical treatments of glass fibres [17,19] demonstrated that the strength regeneration is governed by a dissolution reaction that occurs during the immersion of the fibres in the corrosive solution. In this regard, a controlled dissolution in aqueous HF-solution can be performed to remove the superficial layers of silicate glass [20]. This chemical reaction can not only remove the already damaged surface through a glass dissolution but also modify the pre-existing defects on the glass fibre surface. In the same way, it was shown how an alkaline solution of $\mathrm{NaOH}$ can be sufficiently corrosive to superficially modify the glass fibres [17].

In line with these studies and considering the basalt fibres strength loss after a thermal recycling process [10], the purpose of the present work is to investigate the possibility to regenerate the basalt fibres tensile strength after thermal exposure using two different chemical agents, sodium hydroxide $(\mathrm{NaOH})$ and hydrofluoric acid (HF). The chemical treatments were carried out on fibres previously heat treated at three different temperatures, namely 400,500 and $600{ }^{\circ} \mathrm{C}$. The phenomenon of superficial dissolution [20] is expected to be active also for basalt fibres, due to their similar chemical composition with glass fibres. Moreover, the fracture toughness of these fibres has been investigated to determine if any structural changes occurred in the bulk of the single fibre and if the structural modifications, generated as a result of the chemical treatment, could play a crucial role on the recovery of the fibres strength. In this regard, the focussed ion beam (FIB) milling was used to artificially introduce a notch of known size in the plane perpendicular to the basalt fibre axis [21,22], to understand the strength controlling phenomenon of the chemically treated basalt fibres [23]. A first analysis of the fracture toughness values obtained through tensile tests confirmed the presence of structural changes in the bulk fibre. Additionally, the SEM micrographs of the fibre surfaces clearly showed the effect of surface etching generated by the use of the $\mathrm{NaOH}$ and $\mathrm{HF}$ solutions. 


\section{Materials and Methods}

\subsection{Raw Materials}

The recovery of the mechanical properties was carried out on basalt fibres with a nominal diameter of $13 \mu \mathrm{m}$ and a linear density of 1200 tex. These fibres were provided by Kamenny Vek (Dubna, Russia) as a continuous roving and presented a commercial sizing compatible with epoxy resin.

\subsection{Fibre Heat Treatment}

Three different heat treatments were carried out to simulate the second stage of the thermal recycling process in order to remove the residual char and contaminations from the fibre surface. A tube furnace (Lenton Thermal Designs Ltd., Hope, UK) was used to heat treat the as-received fibre bundles. Thermal treatments were carried out at three temperatures-400, 500 and $600{ }^{\circ} \mathrm{C}$-in air for $25 \mathrm{~min}$. Finally, the fibres were cooled at room temperature outside of the furnace. These experimental conditions were already investigated in a previous work where it was proved that a severe degradation of the basalt fibres occurred [14]. In addition, these thermal treatments are similar to those used by other researchers on glass fibres for comparison purposes [15,16].

\subsection{Fibre Chemical Treatment}

In the present work the mechanical behaviour of regenerated fibres was investigated. After the mentioned heat treatments at different temperatures, basalt fibre bundles weighing $0.1 \mathrm{~g}$ were immersed in a solution of sodium hydroxide $(\mathrm{NaOH})$ or of hydrofluoric acid $(\mathrm{HF})$.

In the case of the $\mathrm{NaOH}$ solution, the molarities $(1.5$ and $3 \mathrm{M})$ and the immersion times (5 and $10 \mathrm{~min}$ ) were varied, while keeping the temperature constant at $90 \pm 5{ }^{\circ} \mathrm{C}$. All the fibres bundles were subsequently drained and rinsed for $1 \mathrm{~min}$, in $150 \mathrm{~mL}$ of $37 \mathrm{wt} \%$ hydrochloric acid $(\mathrm{HCl})$ to remove the residual sodium hydroxide on the fibre surface [16]. Finally, the fibres were rinsed 3 times, $30 \mathrm{~s}$ each, in $150 \mathrm{~mL}$ of deionized water. Once the chemical treatment was completed, the bundles were placed in a furnace and dried to constant mass at $105 \pm 5^{\circ} \mathrm{C}$ for $6 \mathrm{~h}$.

Unlike the alkaline solution, $1 \mathrm{v} \% \mathrm{HF}$ aqueous solution was used for the chemical regeneration in an acid environment [15]. For this treatment, the heat-treated fibres were immersed in $300 \mathrm{~mL}$ of HF solution at room temperature from $30 \mathrm{~s}$ up to $150 \mathrm{~s}$. At the end of the immersion in the acid solution, the fibres were rinsed 3 times, $30 \mathrm{~s}$ each, in $150 \mathrm{~mL}$ of deionized water. Finally, the fibres were dried in a furnace to constant mass at $105 \pm 5^{\circ} \mathrm{C}$ for $20 \mathrm{~min}$.

\subsection{Single Fibre Tensile Testing}

Single fibre tensile tests were performed with a Zwick/Roell Z010 (Zwick/Roell, Ulm, Germany) machine equipped with a $100 \mathrm{~N}$ load cell. Tests were carried out at room temperature, in displacement control, and with at a cross-head speed of $2 \mathrm{~mm} / \mathrm{min}$. At least 60 fibres for each unit (where a unit represents a group of fibres with the same thermal and chemical treatment) were glued onto cardboards with a central window equal to the gauge length. An average diameter for each fibre was obtained by measuring the diameter in six points along the gauge length with a Nikon Eclipse 150L (Nikon, Amsterdam, The Netherlands) optical microscope equipped with Lucia Measurement image analysis software. The system compliance was measured according to ASTM C 1557 standard [24] by using three gauge lengths, i.e., 20, 30 and $40 \mathrm{~mm}$. A two-parameter Weibull distribution was used to statistically analyse the tensile strength data, in accordance with Equation (1):

$$
F(\sigma)=1-\exp \left[-\left(\frac{\sigma}{\sigma_{0}}\right)^{\alpha_{\sigma}}\right],
$$


where $F(\sigma)$ is the probability of failure at a level of stress $\sigma, \alpha_{\sigma}$ is the Weibull modulus and $\sigma_{0}$ represents a scale parameter. The estimator in Equation (2) was used to estimate the probability of failure:

$$
F_{j}=\frac{j-0.5}{N}
$$

where $N$ is the number of tested fibres and $j$ is the rank of the $j$ th data point $[25,26]$. The parameters of the Weibull distribution, i.e., $\sigma_{0}$ and $\alpha_{\sigma}$, were obtained from the intercept and slope of the plot $\ln \{\ln [1 /(1-F(\sigma))]\}$ against $\ln (\sigma)$, respectively.

Moreover, virgin and chemically treated fibres after heat treatment at $600{ }^{\circ} \mathrm{C}$ were mounted onto a conductive cardboard, containing up to five single fibres. An artificial notch was introduced on a plane perpendicular to the single fibre axis, by means of a scanning electron microscope equipped with the focussed ion beam (FIB). Once the notch was made, tensile test machine Favimat+, supplied by Textechno Textile Testing Technology (Mönchengladbach, Germany), was used to carry out single fibre tensile tests, working with a cross-head speed of $2 \mathrm{~mm} / \mathrm{min}$. During the notch production operation, it was possible to measure the diameter of each fibre from SEM images.

\subsection{Focussed Ion Beam (FIB) Milling and Fracture Toughness Test}

A cardboard able to hold up to 5 fibres was carefully connected to a metal support using a copper tape to provide the appropriate electrical paths during the fibre milling operation. A FEI Helios NanoLabTM DualBeamTM 600i (Thermo Fisher Scientific, Hillsboro, OR, USA) system equipped with a FIB was used to introduce artificial notches into the fibres. $\mathrm{Ga}^{+}$ions were accelerated in the FIB system using $30 \mathrm{kV}$ of potential, with the beam current adjusted to $0.43 \mathrm{nA}$. The appropriate beam current was selected to avoid microstructural changes due to ion impact during milling operations. Straight and sharp notches perpendicular to the fibre axis were introduced into the fibres with a depth $\left(a_{0}\right) /$ diameter $(D)$ ratio of approximately 0.2 . The notched fibres were subjected to tensile tests using the experimental set-up previously described (SENT, single edge notch tension).

\subsection{Scanning Electron Microscopy (SEM)}

All the lateral surfaces of the regenerated fibres were examined in order to understand if any superficial changes occurred after the chemical treatments. Furthermore, after the tensile test, all the fracture surfaces of notched fibres were observed to confirm the position of the fracture and verify the quality of the notch. All samples were sputter coated with chromium before being analyzed with a high-resolution field emission scanning electron microscope (Auriga Zeiss, Oberkochen, Germany).

\section{Results and Discussion}

The detrimental effect of the thermal recycling process on basalt fibres has already been widely discussed in the literature [9,10,14]. The results of a previous paper [14] pointed out a large drop in strength of $50 \%$ at $400{ }^{\circ} \mathrm{C}$, reaching a $75 \%$ drop at the maximum temperature of $600{ }^{\circ} \mathrm{C}$. Due to this strength decrease, basalt fibres can no longer be used in a new structural composite material but they can be re-utilized as discontinuous fillers. Therefore, it is necessary to find out suitable solutions to allow the recovery of recycled fibres [27,28]. In this regard, the regenerative effect of different chemical treatments on thermally conditioned basalt fibres was evaluated through tensile tests on single fibres. In particular, the regenerative processes were carried out using an alkaline sodium hydroxide solution $(\mathrm{NaOH})$ or an acid solution of hydrofluoric acid (HF). For both chemical agents, the results showed the beneficial effect on the mechanical strength of the heat-treated basalt fibres. Different treatments were performed for the $\mathrm{NaOH}$ regeneration, modifying each time the concentration $(1.5$ and $3 \mathrm{M})$ of the solution and the duration of the test ( 5 and $10 \mathrm{~min}$ ), always keeping the solution temperature constant at $90 \pm 5{ }^{\circ} \mathrm{C}$. Instead, chemical treatments with $\mathrm{HF}$ were carried out at room temperature, keeping the concentration of the solution constant $(1 \mathrm{v} \%)$, but varying the duration of the immersion from 30 up to $150 \mathrm{~s}$. 
Tables 1 and 2 summarize the results obtained from tensile tests, showing the different regenerability of the two chemical agents used. As shown in Table 1, the chemical treatment using $\mathrm{NaOH}$ alkaline solution was able to increase the tensile strength up to $2366 \mathrm{MPa}$, highlighting a significant regenerative effect. Figure 1 shows that the different regeneration treatments with the $\mathrm{NaOH}$ solution can almost totally or at least partially recover the basalt fibres strength lost during the thermal recycling process. This chemical regenerative capacity becomes less effective with increase of the exposure temperature used during the previous thermal treatments, as reported for glass fibres [16]. In fact, as suggested by Thomason et al. [16], the average fibre strength values of heat treated fibres may represent an upper limit and the actual value is likely much lower [29], experiencing a decrease with increasing conditioning temperature. At the same time, particular attention must be paid to the regenerative capacity of the different $\mathrm{NaOH}$ solutions. In fact, as the concentration of the chemical agent and treatment time increase, a greater recovery of the mechanical strength of the basalt fibres was recorded. Therefore, it is possible to state that the most corrosive solution is the best performing among those investigated, yielding in the case of the heat treatment at $400{ }^{\circ} \mathrm{C}$ a $94 \%$ recovery of the strength previously lost.

Table 1. Average tensile strength for regenerated basalt fibres after $\mathrm{NaOH}$ treatment and Weibull parameters of the strength distribution (standard deviation in parentheses).

\begin{tabular}{|c|c|c|c|c|}
\hline $\begin{array}{l}\text { Heat Treatment } \\
\text { Temperature }\left({ }^{\circ} \mathrm{C}\right)\end{array}$ & $\begin{array}{c}\text { Chemical Treatment } \\
\text { with } \mathrm{NaOH}\end{array}$ & $\begin{array}{c}\text { Tensile Strength } \\
\text { (MPa) }\end{array}$ & $\begin{array}{c}\text { Weibull } \\
\text { Modulus- } \alpha_{\sigma}\end{array}$ & $\begin{array}{c}\text { Scale Parameter- }-\sigma_{0} \\
(\mathrm{MPa})\end{array}$ \\
\hline R.T. & - & $2514.85(276.67)$ & 10.85 & 2634.19 \\
\hline \multirow{5}{*}{400} & - & 1304.77 (304.96) & 4.82 & 1425.17 \\
\hline & $1.5 \mathrm{M}-5 \mathrm{~min}$ & $1753.98(394.36)$ & 5.25 & 1905.02 \\
\hline & $1.5 \mathrm{M}-10 \mathrm{~min}$ & $1653.53(189.30)$ & 10.24 & 1736.76 \\
\hline & $3 \mathrm{M}-5 \mathrm{~min}$ & $1694.83(356.98)$ & 5.53 & 1837.44 \\
\hline & $3 \mathrm{M}-10 \mathrm{~min}$ & $2366.63(327.84)$ & 8.16 & 2511.32 \\
\hline \multirow{5}{*}{500} & - & $1056.67(305.80)$ & 4.16 & 1162.30 \\
\hline & $1.5 \mathrm{M}-5 \mathrm{~min}$ & 1291.53 (299.30) & 5.31 & 1402.48 \\
\hline & $1.5 \mathrm{M}-10 \mathrm{~min}$ & $1327.48(214.57)$ & 7.20 & 1417.86 \\
\hline & $3 \mathrm{M}-5 \mathrm{~min}$ & $1183.72(192.49)$ & 7.33 & 1263.30 \\
\hline & $3 \mathrm{M}-10 \mathrm{~min}$ & 1414.40 (199.43) & 8.63 & 1496.41 \\
\hline \multirow{5}{*}{600} & - & $663.96(166.22)$ & 4.63 & 726.29 \\
\hline & $1.5 \mathrm{M}-5 \mathrm{~min}$ & $852.16(242.65)$ & 4.34 & 939.16 \\
\hline & $1.5 \mathrm{M}-10 \mathrm{~min}$ & 838.42 (182.42) & 5.61 & 908.06 \\
\hline & $3 \mathrm{M}-5 \mathrm{~min}$ & $739.90(163.08)$ & 5.48 & 803.56 \\
\hline & $3 \mathrm{M}-10 \mathrm{~min}$ & $1122.05(315.50)$ & 4.10 & 1236.64 \\
\hline
\end{tabular}

Table 2. Average tensile strength for regenerated basalt fibres after HF treatment and Weibull parameters of the strength distribution (standard deviation in parentheses).

\begin{tabular}{ccccc}
\hline $\begin{array}{c}\text { Heat Treatment } \\
\text { Temperature }\left({ }^{\circ} \mathbf{C}\right)\end{array}$ & $\begin{array}{c}\text { Chemical Treatment } \\
\text { with HF }\end{array}$ & $\begin{array}{c}\text { Tensile Strength } \\
\mathbf{( M P a )}\end{array}$ & $\begin{array}{c}\text { Weibull } \\
\text { Modulus- } \boldsymbol{\alpha}_{\boldsymbol{\sigma}}\end{array}$ & $\begin{array}{c}\text { Scale Parameter- } \boldsymbol{\sigma}_{\mathbf{0}} \\
\mathbf{( M P a})\end{array}$ \\
\hline R.T. & - & $2514.85(276.67)$ & 10.85 & 2634.19 \\
\hline & - & $1304.77(304.96)$ & 4.82 & 1425.17 \\
400 & $30 \mathrm{~s}$ & $1789.97(289.39)$ & 7.31 & 1909.11 \\
& $60 \mathrm{~s}$ & $1630.58(271.17)$ & 7.01 & 1743.09 \\
& $150 \mathrm{~s}$ & $1571.87(281.29)$ & 6.66 & 1685.90 \\
\hline & - & $1056.67(305.80)$ & 4.16 & 1162.30 \\
500 & $30 \mathrm{~s}$ & $1279.32(283.81)$ & 5.43 & 1387.58 \\
& $60 \mathrm{~s}$ & $1351.33(278.03)$ & 5.97 & 1457.70 \\
& $150 \mathrm{~s}$ & $1260.74(276.38)$ & 5.55 & 726.29 \\
& - & $663.96(166.22)$ & 4.63 & 962.34 \\
& $30 \mathrm{~s}$ & $892.49(177.62)$ & 5.96 & 1159.87 \\
& $60 \mathrm{~s}$ & $1073.20(209.79)$ & 5.77 & 1175.79 \\
\hline
\end{tabular}


Figure 2 shows the regenerative ability of HF treatments as a function of treatment duration. Tensile tests confirmed a general improvement of the fibre strength properties after HF treatment, but the plot underlines a strength reduction with increasing chemical treatment time, limiting the recovery to a maximum of $\sim 70 \%$. Thus, the hydrofluoric acid solution allows a partial strength recovery for the basalt fibres, offering smaller improvements compared to the treatments in $\mathrm{NaOH}$ solution. This result points towards a more environmentally friendly regeneration process, excluding the issues related to the use and disposal of harmful HF.

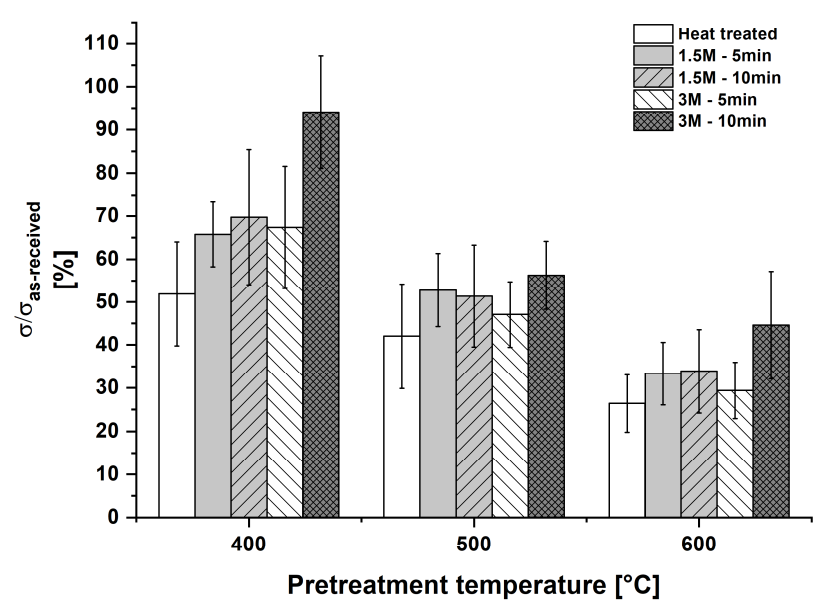

Figure 1. Percentage of strength retention for basalt fibres after $\mathrm{NaOH}$ treatment as a function of pre-treatment temperature.

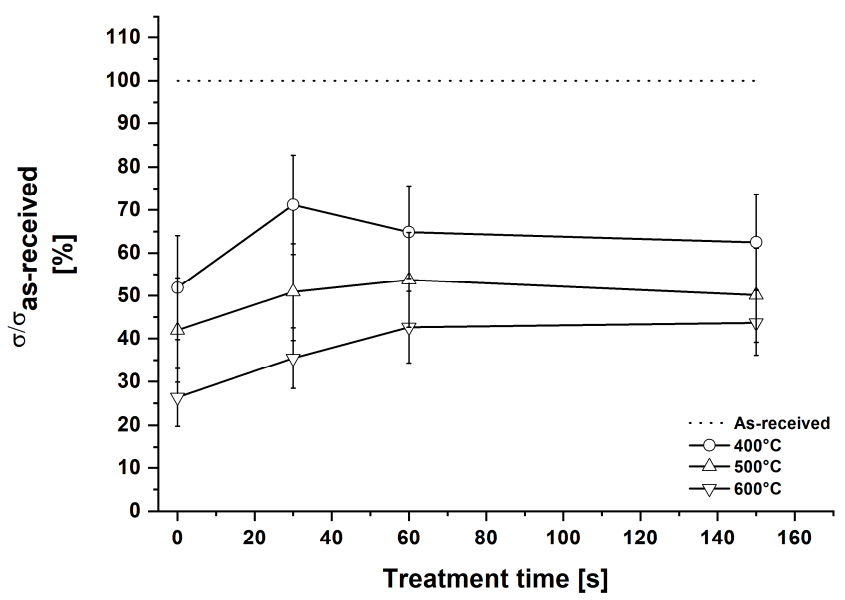

Figure 2. Percentage of strength retention for basalt fibres after HF treatment as a function of treatment time.

Microscopic analysis of the fracture surfaces of tested fibres has already demonstrated that surface flaws are the responsible for the failure of fibres during tensile tests $[10,14]$. Additionally, in this case, the fracture mechanism was not changed by the thermal recycling process and the nature of the flaws was not altered by the high temperature. Considering the fracture surface of the regenerated fibres, the SEM analysis of the cross-section area confirmed the presence of three distinct zones, i.e., mirror, mist and hackle, typical of the fracture mechanism of brittle materials (Figure 3). This behaviour confirms that the failure of regenerated fibres hinges on the presence of superficial flaws even after the chemical treatment. The Weibull distribution of strength for the treatments in alkaline solutions (Figure 4) and for the treatments in acid solutions (Figure 5) underlined a linear trend, thus validating the occurrence of a single population of defects as already shown by untreated fibres $[10,14]$. The homogenization of the basalt fibre surfaces could be responsible for the regeneration 
of the strength lost during the heat treatment. In fact, while the thermal recycling process increased the surface defects size and caused the exposure of the fibre flaws because of the sizing degradation, the subsequent chemical treatment generated a dissolution reaction able to smooth the fibres surface, thus removing the superficial defects.

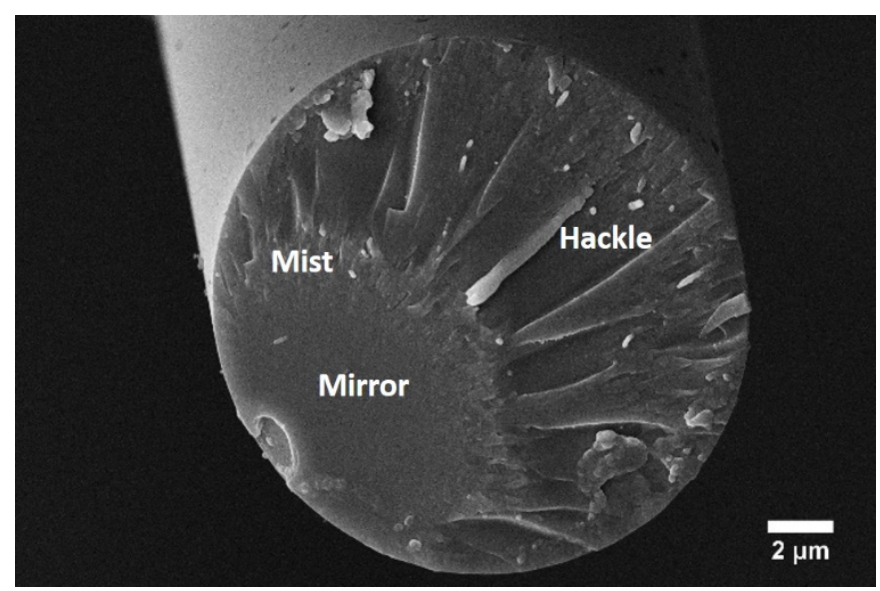

Figure 3. SEM micrograph of fracture surface of a basalt fibre heat treated at $500{ }^{\circ} \mathrm{C}$ and in a $3 \mathrm{M} \mathrm{NaOH}$ solution for $10 \mathrm{~min}$.

(a)

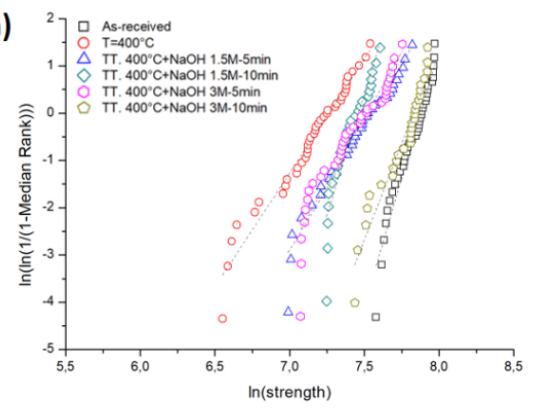

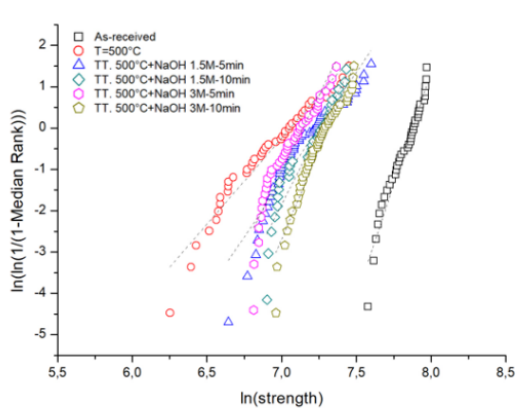

(b)

(c)

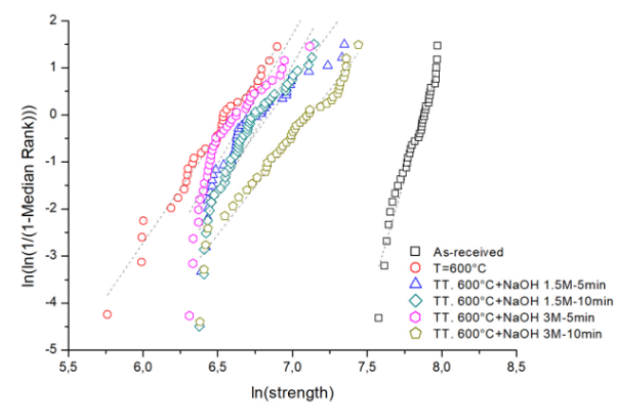

Figure 4. Weibull plots for the tensile strength of basalt fibres after $\mathrm{NaOH}$ treatment as a function of thermal treatment temperature: (a) $400^{\circ} \mathrm{C},(\mathbf{b}) 500^{\circ} \mathrm{C},(\mathbf{c}) 600^{\circ} \mathrm{C}$.

Studies related to the glass fibres strength loss as a result of corrosion phenomena by immersion in an alkaline environment can be extended to basalt fibres. In particular, the corrosion in $\mathrm{NaOH}$ solution is controlled by the dissolution of the silica network $\left(\mathrm{SiO}_{2}\right)$, which is the main component of glass and basalt fibres [30]. The hydroxyl ion $\mathrm{OH}^{-}$in aqueous solution is able to break the siloxane bonds network, generating the migration of the silicates in solution according to the following reaction [31]:

$$
[-\mathrm{Si}-\mathrm{O}-\mathrm{Si}-]+\mathrm{OH}^{-} \rightarrow[-\mathrm{Si}-\mathrm{OH}]+[-\mathrm{SiO}]^{-},
$$


This etching reaction showed negative effects on the as-received fibres [32], while in the case of thermally conditioned fibres, it has positive results by removing surface defects and allowing the recovery of the mechanical strength lost during the heat treatment. In fact, the detrimental effect of alkali treatments on glass fibres is always presented in an attempt to maintain the performance of strong (virgin) fibres for long contact times, while in the present case the effects of shorter alkali treatments are discussed with a view to changing the strength of very weak fibres, as those thermally conditioned, with a limited dissolution of the glass network.

(a)

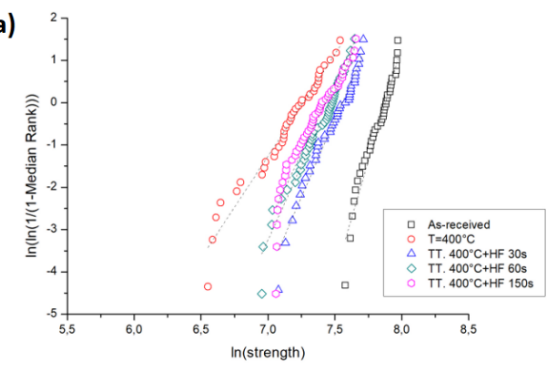

(b)

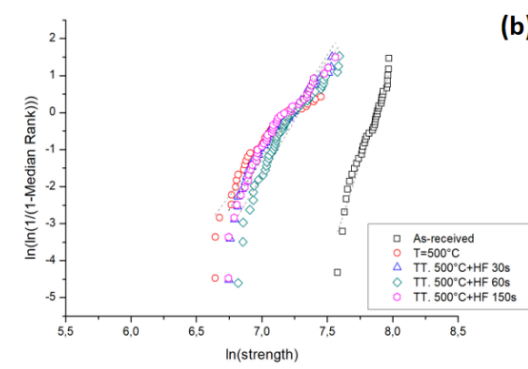

(c)

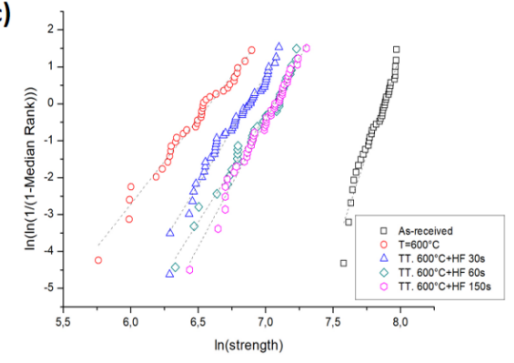

Figure 5. Weibull plots for the tensile strength of basalt fibres after $\mathrm{HF}$ treatment as a function of thermal treatment temperature: (a) $400{ }^{\circ} \mathrm{C},(\mathbf{b}) 500{ }^{\circ} \mathrm{C},(\mathbf{c}) 600^{\circ} \mathrm{C}$.

With regard to the chemical regeneration with HF solution, recent studies on glass fibres highlighted the ability of the hydrofluoric acid solution to remove the damaged surface layer of the fibre previously heat-treated [15]. During this etching reaction, the controlling mechanism is the breakage of the siloxane bonds in the silica network due to the surface adsorption of undissociated $\mathrm{HF}$ molecules and $\mathrm{HF}_{2}{ }^{-}$ ions and the catalytic action of $\mathrm{H}^{+}$ions [20]. The reaction (4) expresses the heterogeneous dissolution of the silica network that occurs as a result of the reaction with HF:

$$
\mathrm{SiO}_{2}+6 \mathrm{HF} \rightarrow \mathrm{H}_{2} \mathrm{SiF}_{6}+2 \mathrm{H}_{2} \mathrm{O}
$$

The dissolution reaction is controlled by the adsorption and the chemisorption kinetics of the reactive species. The etching process not only removes material from the fibre surface, but it is also able to modify the morphology of the surface itself. As already shown for glass fibres [20], the aqueous HF solution transforms the surface with closed flaws into a surface with cusp-like structures. In the present paper, it is supposed that the corrosion produced by HF solution on heat-treated basalt fibres strengthens fibres due to the removal of the damage surface layers. Comparing SEM micrographs of the lateral surfaces of the as-received, heat-treated and regenerated basalt fibres (Figure 6), the ability of the two chemical treatments to remove the surface defects and homogenize the fibre surface can be confirmed. In Figure $6 a$, it is possible to notice how the polymer sizing coating ensures the uniformity of the untreated basalt fibre, offering adequate protection to the fibre. The heat treatment damaged the silane sizing, thus exposing the fibre superficial defects and decreasing the mechanical strength (Figure 6b). As can be clearly seen in Figure $6 c, d$, the chemical treatments smoothened the fibre surface due to the etching reaction promoted by the corrosion occurring in solution. 
The reduction of surface flaw seems to be the controlling mechanism of the regeneration of the basalt fibre tensile strength, but it cannot be ruled out that structural modifications of the bulk fibre might control the mechanical behaviour. To this purpose, fracture properties of regenerated basalt fibres were analysed, by introducing artificial defects on the regenerated basalt fibres using the focused ion beam milling technique [33] (Figure 7).
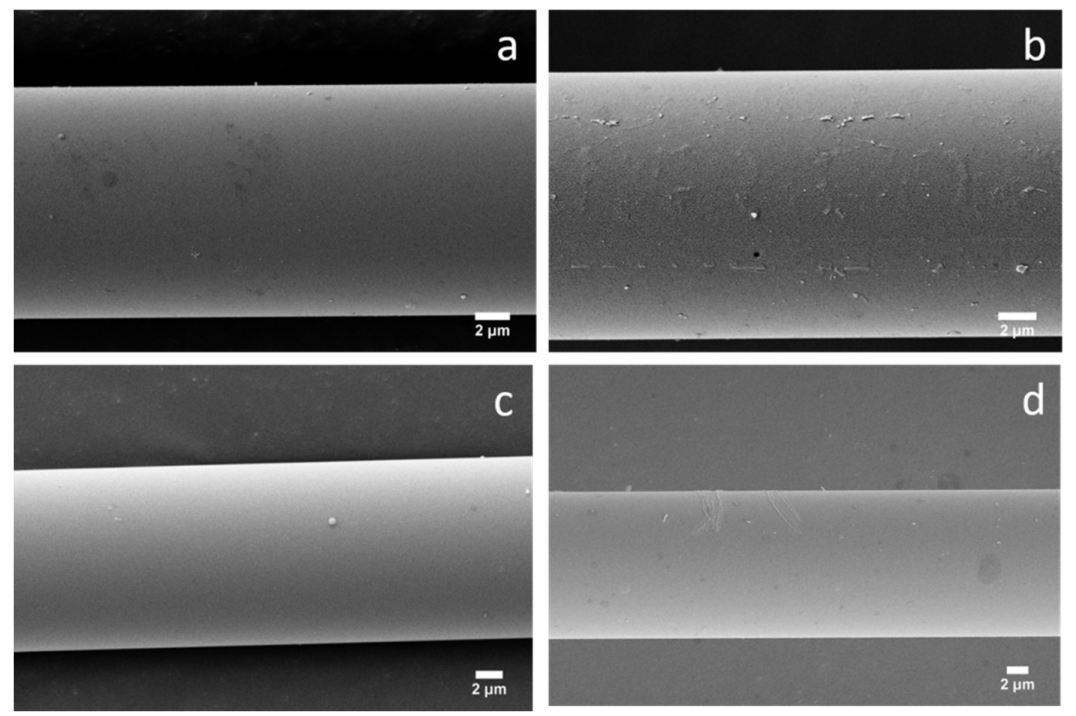

Figure 6. SEM micrographs of (a) as-received basalt fibres, (b) heat-treated at $600{ }^{\circ} \mathrm{C}$, (c) heat treated at $600{ }^{\circ} \mathrm{C}+$ chemically treated in $3 \mathrm{M} \mathrm{NaOH}$ solution for $10 \mathrm{~min}$, (d) heat treated at $600{ }^{\circ} \mathrm{C}+$ chemically treated in HF solution for $2.5 \mathrm{~min}$.

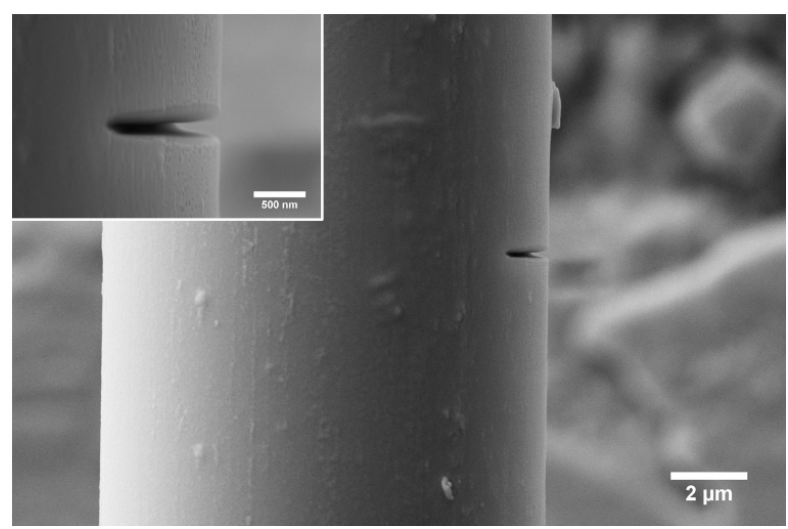

Figure 7. SEM micrographs of artificially notched basalt fibre.

After tensile tests on single notched fibres, the fracture toughness values were evaluated assuming a linear elastic fracture mechanics (LEFM) [34]. Later, the introduction of a straight-fronted edge crack in a cylinder subjected to uniaxial tension along its axis was confirmed by SEM analysis of the regenerated fibre fracture surface (Figure 8 ). The fracture properties of chemically-treated fibres are expressed in terms of mode I fracture toughness $\left(K_{I c}\right)$ [35], according to the Equation (5):

$$
K_{I c}=Y[a / D] \cdot \sigma_{f} \sqrt{\pi a},
$$

where " $a$ " represents the notch depth, " $Y$ " is the stress intensity factor (SIF) or geometric factor, " $D$ " is the fibre diameter and " $\sigma_{f}$ " is the fibre tensile strength. The SIF is calculated for each fibre using the Valiente's equation (Equation (6)), as already done for carbon and basalt fibres [14,21]. This equation 
was obtained by finite element method in a previous work for surface cracks in round bars subjected to tension loading [36]:

$$
Y=1.4408-3.6364 \xi+19.3500 \xi^{2}-34.7849 \xi^{3}+36.8446 \xi^{4},
$$

where $\xi=a / D$ depends on the ratio "notch depth/ fibre diameter" $(a / D)$.

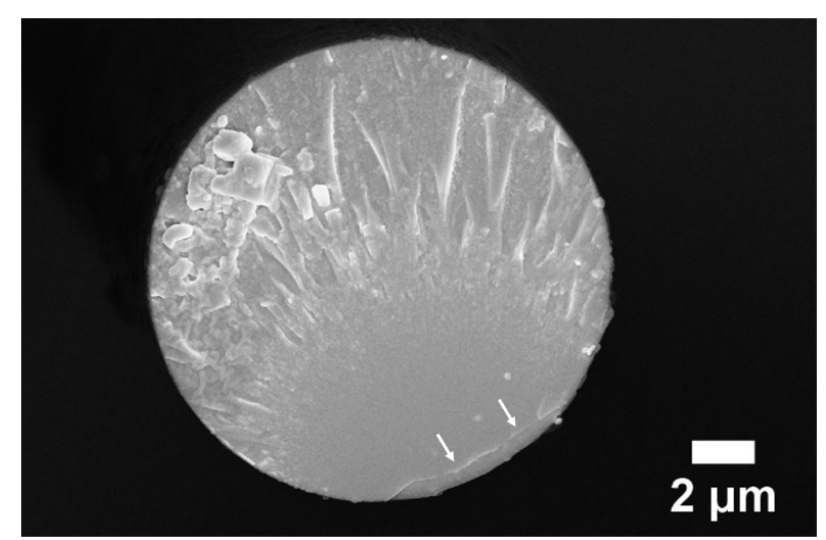

Figure 8. SEM micrograph of the cross-section of an artificially notched basalt fibre after tensile test (white arrows indicate the location of the artificial notch).

Table 3 shows the fracture properties of the basalt fibres regenerated by $\mathrm{NaOH}$ chemical treatments at different concentration and by chemical treatments in HF acid solution. The tensile tests on the single notched fibres were carried out on chemically treated fibres previously conditioned at $600{ }^{\circ} \mathrm{C}$. This temperature was chosen to highlight any structural changes in the bulk fibre during the recycling treatment [37]. For the chemical solution able to guarantee the highest regenerative ability, i.e., the most aggressive solution ( $\mathrm{NaOH} 3 \mathrm{M}-10 \mathrm{~min}$ ), it was possible to obtain a fracture toughness $\left(K_{I c}\right)$ value of $2.53 \pm 0.59 \mathrm{MPa} \sqrt{ } \mathrm{m}$. On the contrary, in the case of HF treatment, the $K_{I c}$ obtained is even higher, equal to $2.88 \pm 0.53 \mathrm{MPa} \sqrt{ } \mathrm{m}$, although the treatment in acid solution on un-notched fibres offered a lower regeneration effect. The aforementioned results on the regenerated fibres, expressed in terms of fracture properties, highlight an increase of the fracture toughness compared to the values obtained for the untreated basalt fibres, $K_{I c}=1.17 \pm 0.45 \mathrm{MPa} \sqrt{\mathrm{m}}$, and for basalt fibres heat-treated at $600{ }^{\circ} \mathrm{C}$, $K_{I c}=1.62 \pm 0.46 \mathrm{MPa} \sqrt{ } \mathrm{m}[14]$. For these reasons, it is confirmed that the increase in strength through chemical treatments is not only due to the superficial dissolution caused by chemical reactions, but also to structural changes occurring in the bulk of the fibres.

Table 3. Fracture characteristic values obtained after SENT tests of untreated, thermally conditioned and regenerated basalt fibres. The values include fibre notch depth/diameter ratio $(a / D)$, geometric factor $(Y)$, residual strength $\left(\sigma_{f}\right)$, fracture toughness $\left(K_{I c}\right)$, expressed as average value of the investigated property (standard deviation).

\begin{tabular}{|c|c|c|c|c|c|c|}
\hline $\begin{array}{c}\text { Temperature } \\
\left({ }^{\circ} \mathrm{C}\right)\end{array}$ & Chemical Treatment & $\mathrm{a} / \mathrm{D}$ & $\mathrm{SIF}-\mathrm{Y}$ & $\begin{array}{c}\text { Residual Strength } \\
\text { (MPa) }\end{array}$ & $\begin{array}{l}\text { Fracture Toughness } \\
(\mathrm{MPa} \sqrt{\mathrm{m}})\end{array}$ & Reference \\
\hline R.T. & - & $0.15(0.06)$ & $1.28(0.16)$ & 420.85 (195.93) & $1.17(0.45)$ & [14] \\
\hline 600 & - & $0.13(0.05)$ & $1.30(0.17)$ & $569.88(168.08)$ & $1.62(0.46)$ & [14] \\
\hline 600 & $\mathrm{NaOH} 1.5 \mathrm{M} 5 \mathrm{~min}$ & $0.10(0.04)$ & $1.26(0.03)$ & $893.86(166.26)$ & $2.14(0.57)$ & This study \\
\hline 600 & $\mathrm{NaOH} 3 \mathrm{M} 10 \mathrm{~min}$ & $0.13(0.04)$ & $1.24(0.02)$ & $984.89(295.63)$ & $2.53(0.59)$ & This study \\
\hline 600 & $\mathrm{HF} 1 \mathrm{v} \% 2.5 \mathrm{~min}$ & $0.16(0.03)$ & $1.24(0.02)$ & $991.16(315.94)$ & $2.88(0.53)$ & This study \\
\hline
\end{tabular}

\section{Conclusions}

In the present work, it has been established that both chemical treatments in alkaline $(\mathrm{NaOH})$ and acid solution (HF) are able to recover the mechanical strength lost during the thermal recycling process. In particular, the 10 min chemical treatment with a 3 molar solution of $\mathrm{NaOH}$ was able to almost 
completely regenerate the strength of heat-treated basalt fibres at $400^{\circ} \mathrm{C}$ for $25 \mathrm{~min}$, featuring a strength recovery of $94 \%$, while this ability decreased with increasing exposure temperature, reaching a value of $45 \%$ for a treatment performed at $600{ }^{\circ} \mathrm{C}$ for $25 \mathrm{~min}$. Alkaline solution proved to be considerably more effective than the acid solution, thus eliminating problems in terms of safety and toxicity related to hydrofluoric acid, especially after treatments at 400 and $500{ }^{\circ} \mathrm{C}$. From morphological investigations, it was noted that the chemical treatments promoted an etching reaction on the fibre surface, reducing the exposed flaws after the sizing degradation during the heat treatment. Data obtained from the tensile tests on single notched fibres showed a significant increase in the fracture toughness for the regenerated fibres, in comparison with as-received and heat-treated basalt fibres. Values of 2.53 and $2.88 \mathrm{MPa} \cdot \mathrm{m}^{1 / 2}$ were obtained for fibres exposed to $600{ }^{\circ} \mathrm{C}$ and subjected to treatments in $\mathrm{NaOH} 3 \mathrm{M}$ for $10 \mathrm{~min}$ and $\mathrm{HF} 1 \mathrm{v} \%$ for $2.5 \mathrm{~min}$, respectively, compared to $1.17 \mathrm{MPa} \cdot \mathrm{m}^{1 / 2}$ for neat basalt fibres. This increase confirms that the observed strength regeneration is due to superficial and bulk structural re-organizations, which deserve specific investigations.

Author Contributions: Conceptualization, F.S., J.T., and C.G.; methodology, F.S., J.T., C.G. and C.S.L.; validation, F.S., J.T., C.G. and C.S.L.; investigation, M.L., L.D.F., and A.F.; resources, F.S., J.T., C.G. and C.S.L.; data curation, J.T., M.L., L.D.F., and A.F; writing—original draft preparation, F.S., M.L., and L.D.F.; writing —review and editing, J.T., A.F., C.G. and C.S.L.; visualization, M.L. and L.D.F.; supervision, F.S., J.T., C.G. and C.S.L. All authors have read and agreed to the published version of the manuscript.

Funding: This research received no external funding.

Conflicts of Interest: The authors declare no conflict of interest.

\section{References}

1. Oliveux, G.; Dandy, L.O.; Leeke, G.A. Current Status of Recycling of Fibre Reinforced Polymers: Review of technologies, reuse and resulting properties. Prog. Mater. Sci. 2015, 72, 61-99. [CrossRef]

2. Jenkins, P.G.; Yang, L.; Liggat, J.J.; Thomason, J.L. Investigation of the strength loss of glass fibre after thermal conditioning. J. Mater. Sci. 2015, 50, 1050-1057. [CrossRef]

3. Singha, K. A Short Review on Basalt Fiber. Int. J. Text. Sci. 2012, 1, 19-28.

4. Deák, T.; Czigány, T. Chemical Composition and Mechanical Properties of Basalt and Glass Fibers: A Comparison. Text. Res. J. 2016, 79, 645-651. [CrossRef]

5. Fiore, V.; Scalici, T.; Di Bella, G.; Valenza, A. A review on basalt fibre and its composites. Compos. Part B Eng. 2015, 74, 74-94. [CrossRef]

6. Militký, J.; Kovačič, V.; Rubnerová, J. Influence of thermal treatment on tensile failure of basalt fibers. Eng. Fract. Mech. 2002, 69, 1025-1033. [CrossRef]

7. Förster, T.; Sommer, G.S.; Mäder, E.; Scheffler, C. Surface, interphase and tensile properties of unsized, sized and heat treated basalt fibres. IOP Conf. Ser. Mater. Sci. Eng. 2016, 139, 012019. [CrossRef]

8. Jenkins, P.G.; Riopedre-Méndez, S.; Sáez-Rodríguez, E.; Yang, L.; James, L. Investigation of the Strength of Thermally Conditioned Basalt and E-Glass Fibres. In Proceedings of the 20th International Conference on Composite Materials, Copenhagen, Denmark, 19-24 July 2015; pp. 19-24.

9. Bhat, T.; Fortomaris, D.; Kandare, E.; Mouritz, A.P. Properties of thermally recycled basalt fibres and basalt fibre composites. J. Mater. Sci. 2018, 53, 1933-1944. [CrossRef]

10. Seghini, M.C.; Sarasini, F.; Tirillò, J. Influence of thermal conditioning on tensile behaviour of single basalt fibres. Compos. Part B Eng. 2018, 132, 77-86.

11. Feih, S.; Boiocchi, E.; Mathys, G.; Mathys, Z.; Gibson, A.G.; Mouritz, A.P. Mechanical properties of thermally-treated and recycled glass fibres. Compos. Part B Eng. 2011, 42, 350-358. [CrossRef]

12. Yang, L.; Thomason, J.L. The thermal behaviour of glass fibre investigated by thermomechanical analysis. J. Mater. Sci. 2013, 48, 5768-5775. [CrossRef]

13. Thomason, J.L.; Kao, C.C.; Ure, J.; Yang, L. The strength of glass fibre reinforcement after exposure to elevated composite processing temperatures. J. Mater. Sci. 2013, 49, 153-162. [CrossRef]

14. Lilli, M.; Rossi, E.; Tirillò, J.; Sarasini, F.; Di Fausto, L.; Valente, T.; González, C.; Fernández, A.; Lopes, C.S.; Moscatelli, R.; et al. Quantitative multi-scale characterization of single basalt fibres: Insights into strength loss mechanisms after thermal conditioning. Mater. Sci. Eng. A 2020, 139963. [CrossRef] 
15. Yang, L.; Sáez, E.R.; Nagel, U.; Thomason, J.L. Can thermally degraded glass fibre be regenerated for closed-loop recycling of thermosetting composites? Compos. Part A Appl. Sci. Manuf. 2015, 72, 167-174. [CrossRef]

16. Thomason, J.L.; Nagel, U.; Yang, L.; Sáez, E. Regenerating the strength of thermally recycled glass fibres using hot sodium hydroxide. Compos. Part A Appl. Sci. Manuf. 2016, 87, 220-227. [CrossRef]

17. Bashir, S.T.; Yang, L.; Anderson, R.; Tang, P.L.; Liggat, J.J.; Thomason, J.L. A simple chemical approach to regenerating the strength of thermally damaged glass fibre. Compos. Part A Appl. Sci. Manuf. 2017, 102, 76-87. [CrossRef]

18. Thomason, J.L.; Yang, L.; Meier, R. The properties of glass fibres after conditioning at composite recycling temperatures. Compos. Part A Appl. Sci. Manuf. 2014, 61, 201-208. [CrossRef]

19. Thomason, J.L.; Kao, C.C.; Nagel, U.; Yang, L. Recover: Regenerating the Strength of Glass Fibres Thermally Recycled From End-of-Life. In Proceedings of the 20th International Conference on Composite Materials, Copenhagen, Denmark, 19-24 July 2015; pp. 19-24.

20. Spierings, G.A.C.M. Wet chemical etching of silicate glasses in hydrofluoric acid based solutions. J. Mater. Sci. 1993, 28, 6261-6273. [CrossRef]

21. Kant, M.; Penumadu, D. Fracture behavior of individual carbon fibers in tension using nano-fabricated notches. Compos. Sci. Technol. 2013, 89, 83-88. [CrossRef]

22. Morishita, K.; Ochiai, S.; Okuda, H.; Inshikawa, T.; Sato, M.; Inoue, T. Fracture toughness of a crystalline silicon carbide fiber (tyranno-SA3). J. Am. Ceram. Soc. 2006, 89, 2571-2576. [CrossRef]

23. Feih, S.; Mouritz, A.P.; Case, S.W. Determining the mechanism controlling glass fibre strength loss during thermal recycling of waste composites. Compos. Part A Appl. Sci. Manuf. 2015, 76, 255-261. [CrossRef]

24. ASTM. C 1557-03 Standard Test Method for Tensile Strength and Young's Modulus of Fibers 1; American Society for Testing and Materials: West Conshohocken, PA, USA, 2013; Volume 3, pp. 1-10.

25. Weibull, W. A statistical distribution function of wide applicability. J. Appl. Mech. 1951, 18, $293-297$.

26. Sullivan, J.D.; Lauzon, P.H. Experimental probability estimators for Weibull plots. J. Mater. Sci. Lett. 1986, 5, 1245-1247. [CrossRef]

27. Jacob, A. Composites can be recycled. Reinf. Plast. 2011, 55, 45-46. [CrossRef]

28. Kennerley, J. Recycling Fibres Recovered from Composite Materials Using a Fluidised Bed Process. Ph.D. Thesis, University of Nottingham, Nottingham, UK, 1998.

29. Thomason, J.L. On the application of Weibull analysis to experimentally determined single fibre strength distributions. Compos. Sci. Technol. 2013, 77, 74-80. [CrossRef]

30. Liu, J.; Jiang, M.; Wang, Y.; Wu, G.; Wu, Z. Tensile behaviors of ECR-glass and high strength glass fibers after $\mathrm{NaOH}$ treatment. Ceram. Int. 2013, 39, 9173-9178. [CrossRef]

31. Wei, B.; Cao, H.; Song, S. Tensile behavior contrast of basalt and glass fibers after chemical treatment. Mater. Des. 2010, 31, 4244-4250. [CrossRef]

32. Scheffler, C.; Förster, T.; Mäder, E.; Heinrich, G.; Hempel, S.; Mechtcherine, V. Aging of alkali-resistant glass and basalt fibers in alkaline solutions: Evaluation of the failure stress by Weibull distribution function. J. Non. Cryst. Solids 2009, 355, 2588-2595. [CrossRef]

33. Ogihara, S.; Imafuku, Y.; Yamamoto, R.; Kogo, Y. Application of FIB technique to introduction of a notch into a carbon fiber for direct measurement of fracture toughness. J. Phys. Conf. Ser. 2009, 191, 012009. [CrossRef]

34. Herraez, M.; Fernandez, A.; Lopes, C.S.; Gonzalez, C. Strength and toughness of structural fibres for composite material reinforcement. Philos. Trans. R. Soc. A Math. Phys. Eng. Sci. 2016, 374, 20150274. [CrossRef]

35. Freiman, S.W.; Mecholsky, J.J. The Fracture of Brittle Materials; John Wiley \& Sons, Inc.: Hoboken, NJ, USA, 2012; ISBN 9781118147757.

36. Toribio, J.; Álvarez, N.; González, B.; Matos, J.C. A critical review of stress intensity factor solutions for surface cracks in round bars subjected to tension loading. Eng. Fail. Anal. 2009, 16, 794-809. [CrossRef]

37. Jenkins, P.G. Understanding physical changes and strength loss of E-glass fibres following exposure to elevated temperatures. Mater. Sci. Technol. 2017, 33, 255-264. [CrossRef]

(C) 2020 by the authors. Licensee MDPI, Basel, Switzerland. This article is an open access article distributed under the terms and conditions of the Creative Commons Attribution (CC BY) license (http://creativecommons.org/licenses/by/4.0/). 